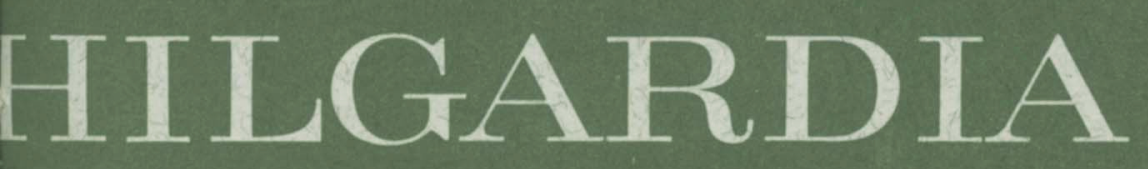

JOURNAL OF AGRICULTURAL SCIENCE PUBLISHED BY HE CALIFORNIA AGRICULTURAL EXPERIMENT STATION

Volume 41, Number $16 \cdot$ January, 1973

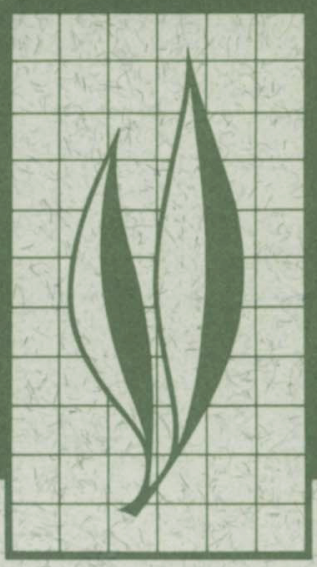

\title{
Cation-Exchange Equilibria on a Yolo Loam
}

H. E. Jensen and K. L. Babcock 


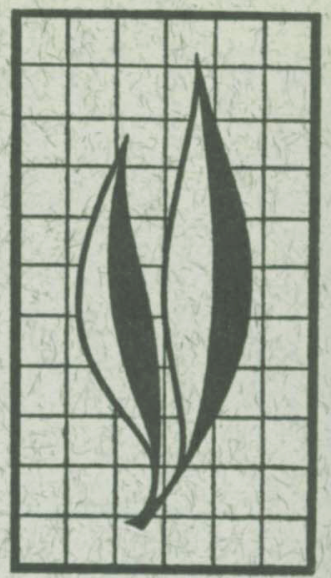

An experimental study was made of several cation-exchange reactions on a Yolo loam soil by means of a leaching procedure. Adsorption isotherms for the $\mathrm{K}-\mathrm{Na}, \mathrm{K}-\mathrm{Mg}, \mathrm{K}-\mathrm{Ca}$, and $\mathrm{Mg}-\mathrm{Ca}$ ion pairs were obtained. An application of thermodynamic equations was used to find the equilibrium constants and free-energy changes for the reactions. Activity coefficients of the adsorbed ions were also calculated. A comparison of various selectivity coefficients was included.

\section{THE AUTHORS:}

H. E. Jensen is Assistant Professor, Hydrotechnical Laboratory, Royal Veterinary and Agricultural College, Copenhagen, Denmark.

K. L. Babcock is Professor of Soil Chemistry, Department of Soils and Plant Nutrition, Berkeley and Soil Chemist in the Experiment Station. 


\section{Cation-Exchange Equilibria on a Yolo Loam ${ }^{1}$}

\section{INTRODUCTION}

IN THE PROCESS of cation-exchange, exchangeable cations adsorbed in the exchanger phase (i.e., the soil particles) are exchanged with cations in the solution phase. When no net transfer of cations between the two phases occurs the system is in a state of equilibrium and the distribution of cations between the two phases may then be described by a cation-exchange equation. Depending on the model assumption, the interface between the two phases may be considered as discrete or diffuse (Babcock, 1963). Many exchange equations and theories based on different assumptions have been proposed, e.g., Kerr (1928), Matson (1929), Vanselow (1932), Gapon (1933), Davis (1950), Eriksson (1952).

Recently, Bolt (1967) gave a review of cation-exchange equations used in soil science. With the exception of the equation derived from double-layer theory (Eriksson, 1952) all of the equations contain an empirical selectivity coefficient which is expected to be constant. However as the models underlying the different equations are still rather simple, there appears to be no reason to expect that any one of the selectivity coefficients will be truly constant over a wide range of conditions. For predictions for practical purposes over a limited range of compositions, one may select the coefficient which best fulfills the condition of constancy under these circumstances.

Argersinger et al. (1950) introduced a thermodynamic approach which was further developed by Gaines and Thomas (1953). Although this approach provides no information about mechanisms and forces of adsorption, it is thermodynamically exact. The Gaines and Thomas theory reduces to that of Argersinger et al. when the activity of water is constant. The theory provides equations from which the thermodynamic equilibrium constant, the standard free-energy change for the exchange reaction, and individual activity coefficients of adsorbed cations can be calculated on the basis of an experimentally determined exchange isotherm, using the extra-thermodynamic assumption that the standard chemical potential of adsorbed cations is completely specified by assigning a mole fraction of unity as the standard state (Babcock, 1963).

In our study particular attenion was paid to the Argersinger thermodynamic approach, and the present paper presents results of experiments designed to provide data in order to verify the assumption inherent in the theory. Furthermore, experimental data are used to test and compare several of the other models referred to above.

\section{MATERIALS AND EXPERIMENTAL METHODS}

The soil used in this study was a Yolo loam from which, in order to avoid possible interference, organic matter had been removed by treating the soil with 10 per cent hydrogen-peroxide solution in a steam-bath. The soil was air-dried,

${ }^{1}$ Submitted for publication February 17, 1972. 
TABLE 1

IONIC STRENGTH AND CATIONIC COMPOSITION OF MIXED SALT SOLUTIONS USED IN THE CATION-EXCHANGE EXPERIMENTS

\begin{tabular}{|c|c|c|c|c|c|c|c|c|c|}
\hline $\begin{array}{l}\text { Equivalent } \\
\text { fraction }\end{array}$ & \multicolumn{4}{|c|}{$\begin{array}{c}\text { Solution concentrations } \\
(\mathrm{meq} / 1)\end{array}$} & $\begin{array}{c}\text { Equivalent } \\
\text { fraction }\end{array}$ & \multicolumn{4}{|c|}{$\begin{array}{c}\text { Solution concentrations } \\
(\mathrm{meq} / 1)\end{array}$} \\
\hline$\underset{x_{K}}{\mathbf{K}-\mathbf{N}}$ & $\mathbf{K}^{+}$ & $\mathrm{Na}^{+}$ & $\mathbf{K}^{+}$ & $\mathrm{Na}^{+}$ & $\underset{x_{\mathbf{M}_{\mathbf{g}}}}{\mathbf{M g}-\mathrm{Ca}}$ & $\mathbf{M g}^{++}$ & $\mathrm{Ca}^{++}$ & $\mathbf{M g}^{++}$ & $\mathrm{Ca}^{++}$ \\
\hline $0.050 \ldots \ldots \ldots \ldots$ & 5 & 95 & 0.5 & 9.5 & 0.100 & 0.66 & 6.00 & 0.06 & 0.60 \\
\hline $0.100 \ldots \ldots \ldots \ldots$ & 10 & 90 & 1.0 & 9.0 & 0.300 & 2.00 & 4.66 & 0.20 & 0.46 \\
\hline $0.200 \ldots \ldots$ & 20 & 80 & 2.0 & 8.0 & 0.500 & 3.33 & 3.33 & 0.33 & 0.33 \\
\hline $0.300 \ldots$ & 30 & 70 & 3.0 & 7.0 & 0.700 & 4.66 & 2.00 & 0.46 & 0.20 \\
\hline $0.500 \ldots$ & 50 & 50 & 5.0 & 5.0 & 0.900 & 6.00 & 0.66 & 0.60 & 0.06 \\
\hline $0.700 \ldots$ & 70 & 30 & 7.0 & 3.0 & 0.950 & 6.33 & 0.33 & 0.63 & 0.03 \\
\hline \multirow{2}{*}{$\underset{\boldsymbol{x}_{\mathbf{K}}}{\mathrm{K}-\mathrm{Ca}}$} & \multicolumn{2}{|c|}{$I=0.001^{*}$} & \multicolumn{2}{|c|}{$I=0.01^{*}$} & \multirow{2}{*}{$\underset{x_{\mathbf{K}}}{\mathbf{K}-\mathbf{M g}^{-}}$} & \multicolumn{2}{|c|}{$I=0.01^{*}$} & \multicolumn{2}{|c|}{$I=0.001^{*}$} \\
\hline & $\mathbf{K}^{+}$ & $\mathrm{Ca}^{++}$ & $\mathbf{K}^{+}$ & $\mathrm{Ca}^{++}$ & & $\mathbf{K}^{+}$ & $\mathbf{M g}^{++}$ & $\mathbf{K}^{+}$ & $\mathbf{M g}^{++}$ \\
\hline 0.000 & 0.00 & 6.66 & 0.00 & 0.66 & 0.000 & 0.00 & 6.66 & 0.00 & 0.66 \\
\hline $0.143 \ldots$ & 1.00 & 6.00 & 0.10 & 0.60 & 0.143 & 1.00 & 6.00 & 0.10 & 0.60 \\
\hline $0.333 \ldots$ & 2.50 & 5.00 & 0.25 & 0.50 & 0.333 & 2.50 & 5.00 & 0.25 & 0.50 \\
\hline 0.500 . & 4.00 & 4.00 & 0.40 & 0.40 & 0.500 & 4.00 & 4.00 & 0.40 & 0.40 \\
\hline 0.778. & 7.00 & 2.00 & 0.70 & 0.20 & 0.778 & 7.00 & 2.00 & 0.70 & 0.20 \\
\hline 0.895 . & 8.50 & 1.00 & 0.85 & 0.10 & 0.895 & 8.50 & 1.00 & 0.85 & 0.10 \\
\hline $0.931 \ldots$ & 9.00 & 0.66 & 0.90 & 0.06 & 0.931 & 9.00 & 0.66 & 0.90 & 0.06 \\
\hline $1.000 \ldots \ldots \ldots \ldots$ & 10.00 & 0.00 & 1.00 & 0.00 & 1.000 & 10.00 & 0.00 & 1.00 & 0.00 \\
\hline
\end{tabular}

$\bullet \mathrm{I}=$ Ionic strength.

crushed to pass a 1-mm sieve, and mixed before subsampling. Eight series of these mixtures, each consisting of eight mixed chloride-salt solutions, were prepared. Table 1 lists the ionic strength of each solution series and the cationic composition of the individual solutions.

The soil was brought to equilibrium with these salt solutions by leaching a soil pad with the solution under study. The leaching runs were carried out in a specially constructed filter funnel which consisted of a cellulose membrane mounted on a coarse glass frit. The inside diameter of the funnel was $36 \mathrm{~mm}$ and the cellulose membrane had a maximum porosity of less than $1 \mu \mathrm{m}$. The procedure was to transfer 0.5 to $1.0 \mathrm{~g}$ of soil to the funnel containing $25 \mathrm{ml}$ of the solution under study. The suspension was carefully stirred by means of a plunger after which soil particles were allowed to settle and form a pad, which was then leached under vacuum filtra- tion with 4 liters of the salt solution being studied. When this was accomplished the vacuum was automatically removed by an electronic device, thus preventing drying and subsequent destruction of the soil pad. Preliminary studies showed that ion-exchange equilibrium was reached between soil and solutions by the time that less than 2 liters of the solutions were used.

After leaching was completed the soil was extracted with $200 \mathrm{ml}$ neutral $1 \mathrm{~N}$ $\mathrm{NH}_{4} \mathrm{OAc}$. The chloride and the cations resulting in the extract were determined and then, using a correction for soluble salts according to the composition of the mixed salt solution, the exchangeable cations were calculated. Calcium, magnesium, and potassium analyses were carried out using atomicabsorption spectrophotometry, whereas sodium was determined by using emission-flame photometry. Chloride was determined by potentiometric titration 
with $\mathrm{AgNO}_{3}$ as described by Johnson and White (1958). All leaching was done in duplicate at room temperature. The activity coefficients in the mixed chloride solutions were estimated from data given by Harned and Owen (1958) using the principle of ionic strength in the usual manner (Babcock, 1963).

\section{RESULTS AND DISCUSSION}

\section{Cation-adsorption isotherms}

Table 2 gives results of the eight series of leaching experiments and the two series of different ionic strength for each of the four pairs of cations under study; in this table $x_{i}$ and $\bar{x}_{i}$ are equivalent fractions of the cation $i$ in the solution and exchanger phase, respectively. $I$ is the ionic strength and CEC the cation exchange capacity, which is taken as the sum of the exchangeable metal ions. The absolute amounts of exchangeable cations can be obtained by multiplying the value of CEC by the respective equivalent fractions of cations in the exchanger phase.

For K-Na and K-Mg exchange equilibria the values of CEC are fairly independent of ionic strength and exchanger composition, whereas for equilibria involving ealcium ions (i.e., $\mathrm{Mg}$ $\mathrm{Ca}$ and $\mathrm{K}-\mathrm{Ca}$ exchange equilibria) the values of CEC increase with ionic strength and with increasing fraction of calcium ions in the exchanger phase. Adsorption of complex eations such as $\mathrm{Ca}(\mathrm{OH})^{+}$and $\mathrm{Mg}(\mathrm{OH})^{+}$would lead to an overestimation of CEC (Bower and Truog, 1940; Babcock et al., 1959). This may explain some of the observed variation in CEC. However, such an effect should also be expected in the K-Mg system, which was not observed.

In the case of homovalent exchange equilibria, the $\mathrm{K}-\mathrm{Na}$ and $\mathrm{Mg}-\mathrm{Ca}$ systems, the equivalent fraction of cations in the exchanger phase is independent of ionic strength. This is not the case for the monodivalent exchange equilibria. For the K-Mg and K-Ca systems, the equivalent fraction of the monovalent cation in the exchanger phase in- creases with increasing ionic strength in the equilibrium solution.

By plotting equivalent fraction of cations in the exchanger phase as a function of the corresponding fraction in solution and drawing smoothed curves, the adsorption isotherms shown in figure 1 were obtained. For the homovalent exchange equilibria which were not influenced by valence effects or by the effects of ionic strength in the concentration range employed, the broken diagonal lines (fig. 1) can be used as non-preference adsorption isotherms. Thus from figure 1 it can be concluded that $\mathrm{K}$ is adsorbed in preference relative to $\mathrm{Na}$, and that $\mathrm{Ca}$ is adsorbed in preference relative to $\mathrm{Mg}$.

Isotherms for the K-Mg and K-Ca systems lie below the diagonal lines. However, this does not necessarily indicate that $\mathrm{Ca}$ and $\mathrm{Mg}$ are adsorbed in preference relative to $\mathrm{K}$. Ionic strength, which cannot appreciably affect the binding energy of the cations (Deist and Talibudeen, 1967), greatly affects the course of the isotherms (Jensen, $1972 a$ ), which in the case of heterovalent exchange equilibria cannot therefore be directly interpreted regarding adsorption preference. For monodivalent exchange equilibria the diagonal line is therefore not considered as a nonpreference adsorption isotherm and therefore it is not plotted.

By using an equation derived by Jensen (1972a) non-preference adsorption isotherms $\left(\triangle G^{\circ}=0\right)$ at ionic strengths corresponding to those used in the experiments have been calculated. Figure 1 shows these isotherms plotted as broken lines. Since the experimental 
exchange isotherms for both the $\mathrm{K}-\mathrm{Mg}$ and $\mathrm{K}$-Ca systems lie above the corresponding non-preference adsorption isotherms, potassium is adsorbed in preference to both $\mathrm{Mg}$ and $\mathrm{Ca}$ according to free energy considerations.

TABLE 2

FRACTIONS OF CATIONS IN SOIL AS A FUNCTION OF THE

CORRESPONDING FRACTIONS IN SOLUTION FOR SEVERAL CATION-EXCHANGE SYSTEMS

\begin{tabular}{|c|c|c|c|c|}
\hline $\begin{array}{c}\text { Solution } \\
\text { equivalent }\end{array}$ & \multicolumn{4}{|c|}{ Soil composition } \\
\hline \multirow{2}{*}{$\underset{x_{\mathbf{K}} \dagger}{\mathrm{K}-\mathrm{Na}}$} & \multicolumn{2}{|c|}{$I=0.010^{*}$} & \multicolumn{2}{|c|}{$I=0.100^{*}$} \\
\hline & $\bar{x}_{\mathbf{K}} \dagger$ & $\underset{\mathrm{meq} / 100_{\mathrm{g}}}{\mathrm{CEC}}$ & $\bar{x}_{\mathbf{K}} \dagger$ & $\begin{array}{c}\text { CEC } \ddagger \\
\mathrm{meq} / 100 \mathrm{~g}\end{array}$ \\
\hline $1.000 \ldots \ldots$ & 1.000 & 18.04 & 1.000 & 18.41 \\
\hline $0.700 \ldots \ldots$ & 0.890 & 18.35 & 0.878 & 18.88 \\
\hline $0.500 \ldots \ldots$ & 0.790 & 18.01 & 0.771 & 17.93 \\
\hline $0.300 \ldots \ldots$ & 0.648 & 17.55 & 0.657 & 18.49 \\
\hline $0.200 \ldots$ & 0.550 & 17.97 & 0.574 & 18.49 \\
\hline $0.100 \ldots \ldots$ & 0.409 & 17.44 & 0.388 & 18.12 \\
\hline $0.050 \ldots \ldots$ & 0.271 & 17.43 & 0.254 & 18.44 \\
\hline $0.000 \ldots \ldots$ & 0.000 & 18.88 & 0.000 & 19.18 \\
\hline $\mathrm{K}-\mathrm{Mg}$ & \multicolumn{2}{|c|}{$I=0.001^{*}$} & \multicolumn{2}{|c|}{$I=0.01^{*}$} \\
\hline $1.000 \ldots \ldots$ & 1.000 & 18.00 & 1.000 & 18.04 \\
\hline $0.931 \ldots \ldots$ & 0.363 & 17.90 & 0.670 & 18.11 \\
\hline $0.895 \ldots \ldots$ & 0.323 & 17.60 & 0.584 & 18.19 \\
\hline $0.778 \ldots \ldots$ & 0.242 & 18.47 & 0.447 & 18.29 \\
\hline $0.500 \ldots$ & 0.125 & 18.26 & 0.251 & 18.49 \\
\hline $0.333 \ldots$ & 0.093 & 18.47 & 0.203 & 18.52 \\
\hline $0.143 \ldots \ldots$ & 0.053 & 18.38 & 0.099 & 18.99 \\
\hline $0.000 \ldots \ldots$ & 0.000 & 18.64 & 0.000 & 18.60 \\
\hline$\underset{x M_{g} \dagger}{\mathrm{Mg}_{\mathbf{g}}-\mathrm{Ca}}$ & $\bar{x}_{M_{g}} \dagger$ & & $\bar{x}_{M_{g}} \dagger$ & \\
\hline $1.000 \ldots \ldots$ & 1.000 & $\begin{array}{l}18.64 \\
18.08\end{array}$ & $\begin{array}{l}1.000 \\
0.912\end{array}$ & $\begin{array}{l}18.60 \\
19.35\end{array}$ \\
\hline $0.800 \ldots \ldots$ & 0.831 & 18.29 & 0.843 & 19.28 \\
\hline $0.700 \ldots \ldots$ & 0.594 & 17.98 & 0.602 & 19.18 \\
\hline $0.500 \ldots \ldots$ & 0.378 & 17.85 & 0.374 & 20.21 \\
\hline $0.300 \ldots \ldots$ & 0.210 & 17.85 & 0.194 & 21.23 \\
\hline $0.100 \ldots \ldots$ & 0.066 & 18.80 & 0.060 & 21.68 \\
\hline $0.000 \ldots \ldots$ & 0.000 & 19.00 & 0.000 & 21.20 \\
\hline 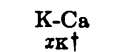 & $\bar{x} \mathbf{k} \dagger$ & & $\bar{x} \mathbf{k} \dagger$ & \\
\hline $1.000 \ldots$ & 1.000 & 18.00 & 1.000 & 18.60 \\
\hline $0.931 \ldots$ & 0.302 & 17.80 & 0.587 & 18.76 \\
\hline 0.895 . & 0.255 & 17.90 & 0.500 & 18.20 \\
\hline $0.778 \ldots \ldots$ & 0.200 & 18.17 & 0.341 & 19.40 \\
\hline $0.500 \ldots \ldots$ & 0.120 & 18.65 & 0.162 & 20.45 \\
\hline $0.333 \ldots \ldots$ & 0.084 & 18.79 & 0.128 & 20.64 \\
\hline $0.143 \ldots \ldots$ & 0.054 & 18.89 & 0.054 & 20.82 \\
\hline $0.000 \ldots \ldots$ & 0.000 & 19.00 & 0.000 & 21.20 \\
\hline
\end{tabular}

- Ionic strength.

$\dagger$ Equivalent fraction.

‡ Cation-exchange capacity.
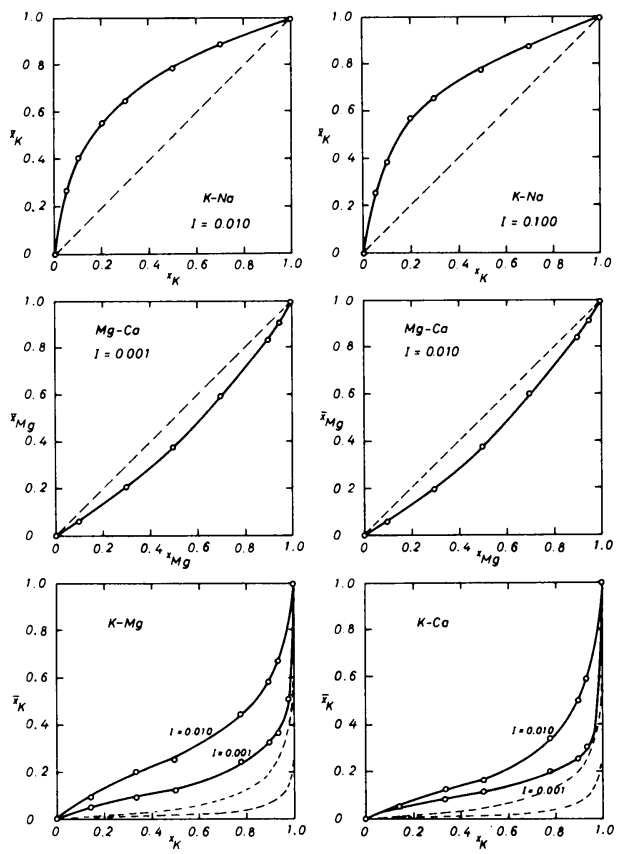

Fig. 1. Cation-adsorption isotherms for several cation-exchange systems. $x=$ equivalent fraction in solution. $\bar{x}=$ equivalent fraction in soil. Broken lines represent nonpreference adsorption isotherms.

\section{Application of 2-phase models}

Assuming the system to consist of two discrete phases (i.e., an exchanger phase and a solution phase) the law of mass-action can be applied. The process of cation exchange may be represented as an interchange of ions between the exchanger phase and the solution phase as follows:

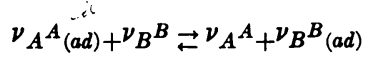

The $\vee$ with subscripts $A$ and $B$ represent numbers of reacting ions $A$ and $B$, respectively, $(a d)$ denotes ions in the exchanger phase, while absence of suffix denotes ions in solutions. Assuming the activity of water to be constant, the standard free-energy change, $\triangle G^{\circ}{ }_{(B-A)}$, the thermodynamic equilibrium con- 
stant, $K_{(B-A)}$, and the activity of cations, $a_{i}$, are related by the following equation:

$$
\begin{aligned}
& \frac{\mathrm{a}_{B_{(\mathrm{Bd})}^{B}}^{\nu} \mathrm{a}_{A}^{\nu}}{a_{A_{(\mathrm{ad})}^{A}}^{\nu} a_{B}^{\nu}} \\
& =\exp \left(-\frac{\Delta G_{(B-A)}^{\circ}}{R T}\right)=K_{(B-A)}
\end{aligned}
$$

in which $R$ and $T$ are the gas constant and the absolute temperature, respectively.

In order to obtain a cation-exchange equation a theory must be found for the activity of ions in the exchanger phase. Vanselow (1932) assumed that the exchanger phase could be treated in analogy with an ideal solid solution, according to which activities of adsorbed ions are set equal to their mole fraction, $N_{i}$, in the exchanger phase. Argersinger et al. (1950) extended Vanselow's theory to non-ideal exchangers and introduced activity coefficients, $f_{i}$, for adsorbed ions defined as

$$
f_{i}=\frac{a_{i}}{N_{i}}
$$

Substituting equation [3] into equation [2] the following equation is obtained:

$\frac{f_{B}^{\nu} N_{B}^{\nu} a_{A}^{\nu}}{f_{A}^{\nu} N_{A}^{\nu} a_{B}^{\nu}}=\frac{f_{B}^{\nu}{ }^{\nu^{B}}}{f_{A}^{\nu}} K_{v(B-A)}=K_{(B-A)}$

The $k_{v(B-A)}$ defined by equation [4] may be called a selectivity coefficient. Applying the Gibbs-Duhem equation to the exchanger phase and combining with equation [4], the following equations are obtained using a mole fraction of unity as the standard state for adsorbed ions, Argersinger et al. (1950):

$$
\begin{gathered}
\nu_{A} \ln f_{A}=\bar{x}_{B} \ln k_{v(B-A)}-\int_{0}^{\bar{x}_{B}} \ln k_{v(B-A)} d \bar{x}_{B} \\
\nu_{B} \ln f_{B}=\left(\bar{x}_{B}-1\right) \ln k_{v(B-A)}-\int_{0}^{1} \ln k_{v(B-A)} d \bar{x}_{B} \\
\ln K_{(B-A)}=\int_{0}^{1} \ln k_{v(B-A)} d \bar{x}_{B}
\end{gathered}
$$

In these equations $\bar{x}_{B}$ is the equivalent fraction of $B$ in the exchanger phase. Thus, if $K_{v(B-A)}$ is known as a function of $\bar{x}_{B}$, individual activity coefficients of the adsorbed cations and the thermodynamic equilibrium constant can be calculated by integration of equations [5], [6], and [7], respectively.

From the smoothed curves for the isotherms (fig. 1) values of the equivalent fractions of $\mathrm{B}$ in solution $x_{B}$ were read off for selected values of equivalent fraction of $B$ in the exchanger phase, $\bar{x}_{B}$, of $0.1,0.2, \ldots, 0.9$. Then the selectivity coefficients, $k_{v(B-A)}$, for the four pairs of cations considered were calculated from equation [4]. The results are given in table 3 , except for the $\mathrm{K}-\mathrm{Ca}$ system at the smallest ionic strength for which values were not calculated because of difficulties in reading the correct values of $\bar{x}_{\mathrm{K}}$, especially at high values of $x_{\mathrm{K}}$. From table 3 it appears that for all systems, save the one in which potassium is absent, the values of $k_{v(B-A)}$ are not constant but always decrease with increasing degree of potassium saturation. For the Mg-Ca system, however, the selectivity coefficient is constant and independent of exchanger composition. Thus, the concept of nonideality is associated not only with the nature of the exchanger itself but also with the nature of the cations involved. For the present soil the exchanger would be regarded as an ideal exchanger when the Mg-Ca systems are considered, but as a non-ideal exchanger when the $\mathrm{K}-\mathrm{Na}, \mathrm{K}-\mathrm{Mg}$, and $\mathrm{K}-\mathrm{Ca}$ systems are con- 
TABLE 3

SELECTIVITY COEFFICIENTS, ACTIVITY COEFFICIENTS OF ADSORBED CATIONS, AND THERMODYNAMIC EQUILIBRIUM CONSTANTS FOR SEVERAL CATION-EXCHANGE SYSTEMS

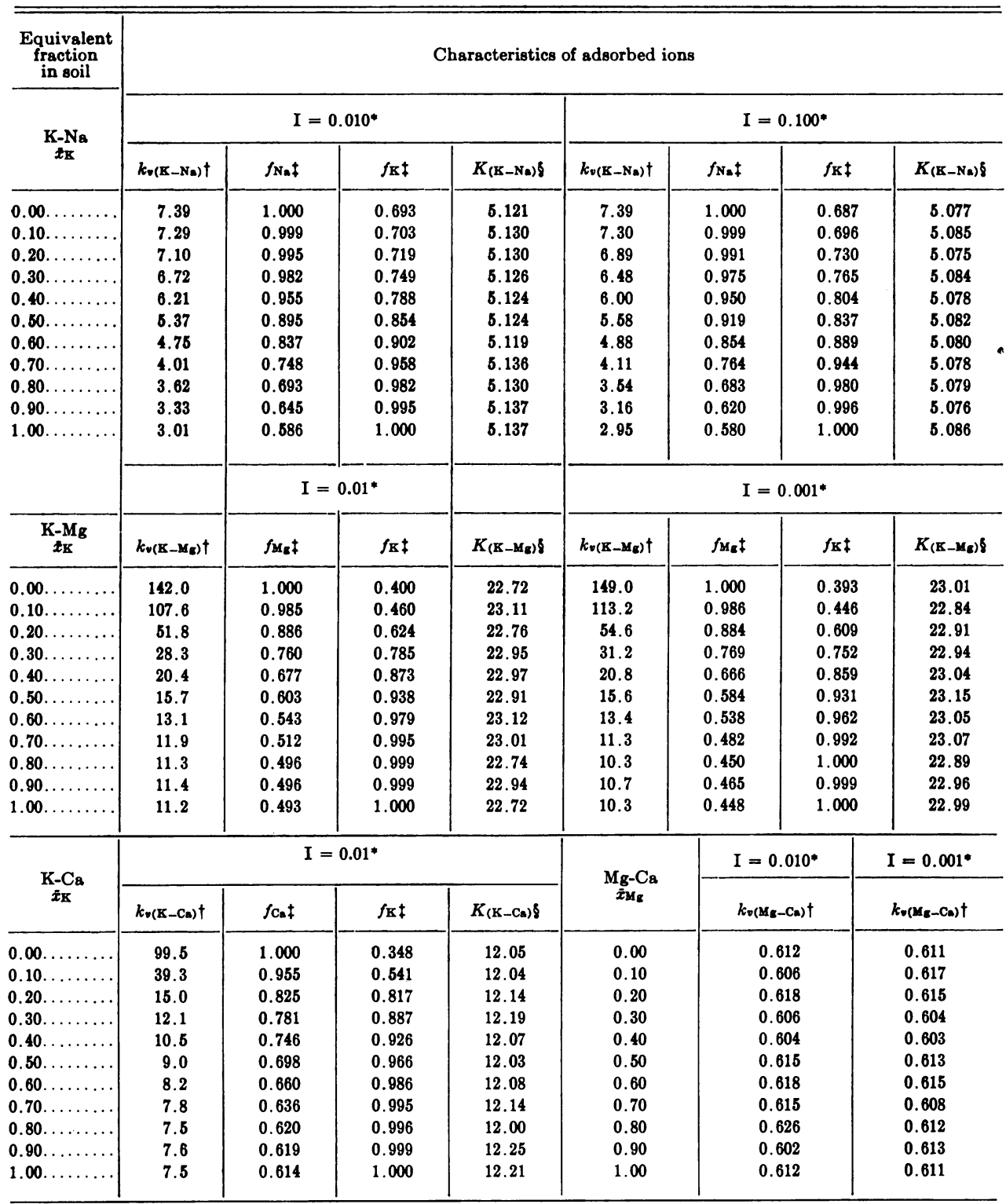

-Ionic strength.

tSelectivity coefficient.

Activity coefficient.

Equilibrium constant. 
sidered. The non-ideality in the present case therefore seems to be associated with the nature of the potassium ion, as it appears only in the systems where potassium ions are present. Such behavior could be associated with the presence of an illitic type of clay minerals, but X-ray diffraction pattern of clays from the Yolo series shows it to be predominantly montmorillonitic (Krishnamoorthy and Overstreet, $1950)$. Due to the variation in $k_{v(B-A)}$ with exchanger composition it is diffcult to compare with results in literature for which the exchanger composition is not given. Values of $k_{v \text { (Mg-Ca) }}$ of $0.61,0.76$, and 0.92 for Wyoming bentonite, Yolo clay, and Utah bentonite, respectively, have been reported (Krishnamoorthy and Overstreet, 1950, and Tabik et al., 1962), which are comparable to the value of 0.61 obtained in the present study. For Yolo clay, Krishnamoorthy and Overstreet (1950) obtained results from which a value of $k_{v(\mathrm{~K}-\mathrm{Na})}$ of 3.33 can be derived. According to results obtained in the present study such a value corresponds to an ex. changer composition of 10 per cent $\mathrm{Na}$ and 90 per cent $\mathrm{K}$ (table 3 ).

From table 3 it also appears that the selectivity coefficients are fairly independent of ionic strength. This is also evident from figure 2 where the logarithm of the selectivity coefficients for the $\mathrm{K}-\mathrm{Na}$ and $\mathrm{K}-\mathrm{Mg}$ systems, respectively, are plotted as a function of the degree of potassium saturation. The thermodynamic equilibrium constants, $K_{(B-A)}$, for the different systems were obtained from plots of $\ln k_{v(B-A)}$ against $\bar{x}_{B}$, using graphical integration of equation [7], applying the trapezoidal rule. Then from equation [2] the standard free energy change, $\Delta G^{\circ}{ }_{(B-A)}$, was calculated. The results are shown in table 4 ; it is evident that the experimental values of $\Delta G^{\circ}{ }_{(B-A)}$ and $K_{(B-A)}$ for the various systems considered are determined independently of ionic strength. The negative value of $\Delta G^{\circ}{ }_{(B-A)}$ for the
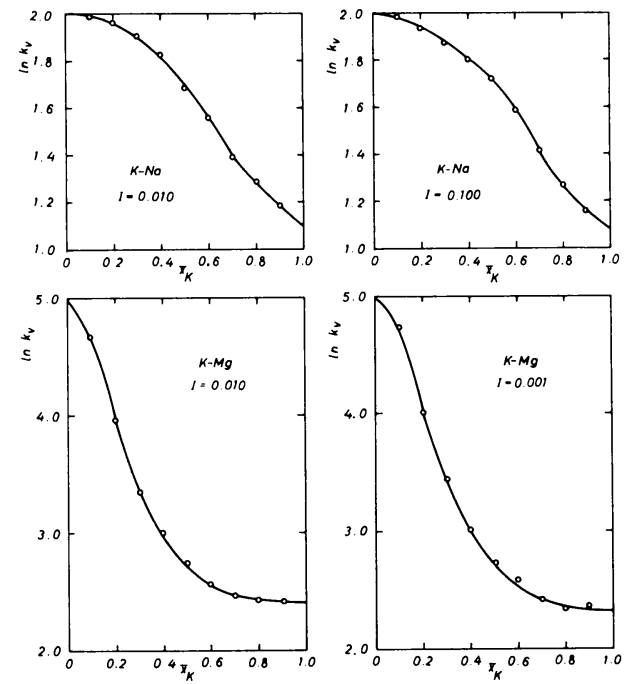

Fig. 2. The Vanselow selectivity coefficient $k_{v}$ plotted against the mole fraction in the exchanger phase $\bar{x}$ for several cation-exchange systems.

$\mathrm{K}-\mathrm{Na}, \mathrm{K}-\mathrm{Mg}$, and $\mathrm{K}-\mathrm{Ca}$ systems implies that reaction [1] would proceed to the right from the standard states, thus forming $\mathrm{K}$-soil from $\mathrm{Na}$-soil, $\mathrm{Mg}$-soil, and Ca-soil, respectively. It is generally believed that calcium and magnesium as divalent ions are adsorbed in preference relative to the monovalent potassium ion, but this is not the case in several soils according to the free-energy changes. Values of $\triangle G^{\circ}{ }_{(\mathrm{K}-\mathrm{Ca})}$ for soils and clays of the same order of magnitude as the value obtained in the present study have been reported by Deist and Talibudeen (1967a, 1967b), Hutcheon (1966), and Jensen (1972b). The value of $\Delta G^{\circ}{ }{ }_{\text {Mg-Ca) }}$ is positive which implies that reaction [1] could proceed to the left from the standard states, thus forming a Ca-soil from a $\mathrm{Mg}$-soil.

Additivity is a necessary requirement for thermodynamic consistency. In order to satisfy this requirement the experimental data must satisfy the following relation:

$$
\begin{aligned}
& \Delta G_{(\mathrm{K}-\mathrm{Ca})}^{\circ} \\
& \quad=\Delta G_{(\mathrm{Mg}-\mathrm{Ca})}^{\circ}+\Delta G_{(\mathrm{K}-\mathrm{Mg})}^{\circ}
\end{aligned}
$$


TABLE 4

STANDARD FREE-ENERGY CHANGE AND THERMODYNAMIC EQUILIBRIUM CONSTANTS FOR SEVERAL CATION-EXCHANGE SYSTEMS

\begin{tabular}{|c|c|c|c|c|c|c|c|c|}
\hline \multirow{2}{*}{$\begin{array}{c}\begin{array}{c}\text { Ionic } \\
\text { strength }\end{array} \\
\mathrm{I}\end{array}$} & \multicolumn{4}{|c|}{ Standard free-energy change } & \multicolumn{4}{|c|}{ Equilibrium constants } \\
\hline & $\Delta G^{\circ}{ }_{\left(\mathrm{K}-\mathrm{Na}_{\mathrm{a}}\right)}$ & $\Delta G^{\circ}{ }_{\left(\mathrm{M}_{\mathbf{B}}-\mathrm{C}_{\mathbf{a}}\right)}$ & $\Delta G^{\circ}{ }_{\left(\mathrm{K}-\mathrm{Mg}_{\mathrm{g}}\right)}$ & $\Delta G^{\circ}{ }_{\left(\mathrm{K}-\mathrm{C}_{\mathbf{a}}\right)}$ & $K_{(\mathrm{K}-\mathrm{Na})}$ & $K_{\left(\mathrm{Mg}_{\mathrm{g}-\mathrm{C}}\right)}$ & $K(\mathrm{~K}-\mathrm{Mg})$ & $K\left(\mathrm{~K}-\mathrm{C}_{\mathbf{s}}\right)$ \\
\hline 0.001 & - & 291 & -1856 & - & - & 0.61 & 22.93 & - \\
\hline 0.010. & -968 & 291 & -1854 & -1474 & 5.12 & 0.61 & 22.85 & 12.04 \\
\hline $0.100 \ldots$ & -963 & - & - & - & 5.08 & - & - & - \\
\hline
\end{tabular}

Table 4 shows that the data satisfy this requirement within reasonable limits of experimental uncertainty. Using this triangular rule, values of $k_{v(\mathrm{Na}-\mathrm{Ca})}$ and $k_{v(\mathrm{Na}-\mathrm{Mg})}$ can be calculated from the results in table 3 . The respective values calculated in this way appear to be fairly constant in a range of $\bar{x}_{\mathrm{Na}}$ from 0.2 to 0.8 , which suggests ideal exchanger behavior also for (Na-Ca) and (Na-Mg) systems in contrast to the non-ideality of the corresponding potassium systems.

The activity coefficients for the adsorbed ions were obtained by integration of equations [5] and [6]; results are listed in table 3 . For the $\mathrm{K}-\mathrm{Na}$ and $\mathrm{K}-\mathrm{Mg}$ systems the data are presented graphically in figure 3 ; in accordance with the theory activity coefficients are independent of ionic strength. By using the obtained activity coefficients for adsorbed ions and the corresponding selectivity coefficients, the values of the thermodynamic equilibrium constant were recalculated by using equation [4]. At each exchanger composition the value should agree with the value found $\bar{b} y$ integrating over all points in equation [7] the values which are listed in table 4. In all cases the agreement is excellent. However, it should be realized that this agreement does not confirm the validity of the assumptions inherent in the theory; it confirms only the consistency in the calculations. Applicability of the
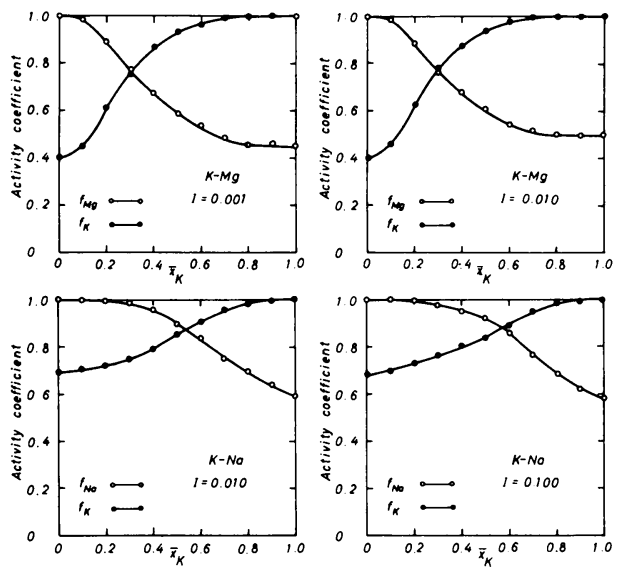

Fig. 3. Activity coefficients or adsorbed cations plotted against the mole fraction in the exchanger phase $\bar{x}$ for several cation-exchange systems.

theory is demonstrated by the fact that the various parameters which can be obtained are independent of ionic strength. Even though the perspective for interpretative usage of individual activity coefficients as obtained by this method may be limited (El-Sayed et al., 1970 ) it is appropriate to summarize experimental data in terms of a plot relating values of $k_{v(B-A)}, f_{B}$, and $f_{A}$ to the exchanger composition.

Many equations have been proposed to describe monodivalent exchange equilibria. Among these are the following four equations in which $\mathrm{B}$ and $\mathrm{A}$ are assumed to be monovalent and divalent cations, respectively: 


$$
\begin{gathered}
\frac{N_{B}^{2} a_{A}}{N_{A} a_{B}^{2}}=k_{v(B-A)} \\
\frac{\bar{x}_{B} \sqrt{a_{A}}}{\bar{x}_{A} a_{B}}=k_{g(B-A)} \\
\frac{n_{B}^{2} a_{A}}{n_{A} a_{B}^{2}\left(n_{A}+q n_{B}\right)}=k_{d(B-A)} \\
\frac{\bar{x}_{B}^{2} a_{A}}{\bar{x}_{A} a_{B}^{2}}=k_{e(B-A)}
\end{gathered}
$$

Equations [9], [10], and [11] have been introduced by Vanselow (1932), Gapon (1933), and Davis (1950), re- spectively; equation [12] has been used by Gaines and Thomas (1955). In equation [11] $n_{i}$ is moles of adsorbed ions and $q$ is a function of the assumed number of nearest neighbors of adsorbed ions which are assumed to be localized. The different ion exchange equations rest on different model assumptions, and if the assumptions underlying a given equation are met by a particular cation exchanger, the respective exchange "constant" should yield a constant value independent of exchanger composition.

Comparing the exchange constants defined above, the following equation is found:

$$
\begin{aligned}
k_{v(B-A)}=k_{e(B-A)} & \frac{4}{1+\bar{x}_{B}}=k_{o(B-A)}^{2} \frac{4-4 \bar{x}_{B}}{1+\bar{x}_{B}} \\
& =k_{d(B-A)}^{\prime} \frac{2+2 \bar{x}_{B}}{3+\bar{x}_{B}}=k_{d(B-A)}^{\prime \prime} \frac{3+3 \bar{x}_{B}}{5+\bar{x}_{B}}
\end{aligned}
$$

In this equation $k_{d(B-A)}^{\prime}$ and $k^{\prime \prime}{ }_{d(B-A)}$ are based on an assumed number of nearest neighbors of adsorbed ions of 4 and 6 , respectively.

Table 5 lists relative values of the different exchange constants (assuming the Vanselow selectivity coefficient to be constant and unity). In the present study the Vanselow selectivity coefficients for $\mathrm{K}-\mathrm{Mg}$ and $\mathrm{K}$-Ca systems decrease with potassium saturation. Since the values of the various constants rela- tive to those of the Vanselow selectivity coefficient increase with $\bar{x}_{B}$ (table 3 ), each of them would give a more constant value for the systems considered than those of the Vanselow selectivity coefficient. Although its derivation seems to be a bit strained, it appears that $k_{g(B-A)}$ among the constants considered fulfills best the condition of constancy, and

\begin{tabular}{|c|c|c|c|c|c|}
\hline \multirow{2}{*}{$\begin{array}{c}\begin{array}{c}\text { Soil equivalent } \\
\text { fraction }\end{array} \\
x B\end{array}$} & \multicolumn{5}{|c|}{ Selectivity coefficients } \\
\hline & $k_{v(B-A)}$ & $k_{e(B-A)}$ & $k_{g(B-A)}$ & $k_{d(B-A)}^{\prime}$ & $k^{\prime \prime} d(B-A)$ \\
\hline $0.1 \ldots \ldots \ldots \ldots \ldots \ldots$ & 1.0 & 0.275 & 0.553 & 0.709 & 0.647 \\
\hline $0.2 \ldots \ldots \ldots \ldots \ldots \ldots$ & 1.0 & 0.300 & 0.612 & 0.750 & 0.692 \\
\hline $0.3 \ldots \ldots \ldots \ldots \ldots \ldots$ & 1.0 & 0.325 & 0.681 & 0.789 & 0.736 \\
\hline $0.4 \ldots \ldots \ldots \ldots \ldots \ldots \ldots$ & 1.0 & 0.350 & 0.764 & 0.824 & 0.778 \\
\hline $0.5 \ldots \ldots \ldots \ldots \ldots \ldots$ & 1.0 & 0.375 & 0.866 & 0.857 & 0.818 \\
\hline $0.6 \ldots \ldots \ldots \ldots \ldots$ & 1.0 & 0.400 & 1.000 & 0.889 & 0.857 \\
\hline $0.7 \ldots \ldots \ldots \ldots \ldots$ & 1.0 & 0.425 & 1.190 & 0.919 & 0.895 \\
\hline $0.8 \ldots \ldots \ldots \ldots \ldots$ & 1.0 & 0.450 & 1.500 & 0.947 & 0.931 \\
\hline $0.9 \ldots \ldots \ldots \ldots \ldots \ldots \ldots$ & 1.0 & 0.475 & 2.179 & 0.974 & 0.966 \\
\hline
\end{tabular}
therefore it is possible that it mav have practical applications in this particular Yolo soil.

TABle 5

RELATIVE VALUES OF DIFFERENT SELECTIVITY COEFFICIENTS 
Application of double-layer theory

Cation-exchange equations which contained an exchange constant to be determined experimentally were discussed in the previous section. The thermodynamic equilibrium constant $K_{(B-A)}$ and the standard free energy change $\triangle G^{\circ}{ }_{(B-A)}$ are also to be experimentally determined. The cation-exchange equation derived from double-layer theory (Eriksson, 1952) offers a means of calculating the coulombic energy component of the total standard free energy change (Jensen, 1972c). From this an estimation of the relative contribution of coulombic and non-coulombic interaction to the total interaction between ions and colloid can be made. The equation derived by Eriksson is:

$$
\bar{x}_{B}=\frac{r}{\delta \sqrt{\beta}} \operatorname{Sinh}^{-1}\left(\frac{\delta \sqrt{\beta}}{r+4 v \sqrt{c_{A}}}\right)
$$

in which $B$ and $A$ are mono- and divalent cations, respectively, $\sigma$ and $\beta$ are surface charge density, meq $/ \mathrm{cm}^{2}$, and a constant equal to $10.8 \times 10^{14} \mathrm{~cm} / \mathrm{mmole}$, respectively; $c$ is concentration in moles $/ 1$; and $v$ is related to the interaction between clay particles and is often conventionally taken as unity, which corresponds to infinite distance, whereas $r=c_{B} / \sqrt{c_{A}}$.

By using activities rather than concentrations, and the activity ratio, $r$, rather than the concentration ratio, and assuming a surface charge density of $1.1 \times 10^{-7} \mathrm{meq} / \mathrm{cm}^{2}$, which corresponds to that of montmorillonite, the relation between $x_{\mathrm{K}}$ and $\mathrm{r}^{\prime}=a_{\mathrm{K}} / \sqrt{a_{\mathrm{Ca}}}$ was obtained from equation [14]. The results are shown in figure 4 as a broken line. As the activity coefficients for $\mathrm{Ca}$ and Mg ions in solution are of similar magnitude, the theoretical relation applies equally well to the $\mathrm{K}-\mathrm{Mg}$ systems. In figure 4 the experimental values of $\bar{x}_{\mathrm{K}}$ are ploted as a function of $r^{\prime}$ for both $\mathrm{K}-\mathrm{Ca}$ and $\mathrm{K}-\mathrm{Mg}$ systems. Even though the theoretical and experimental rela-

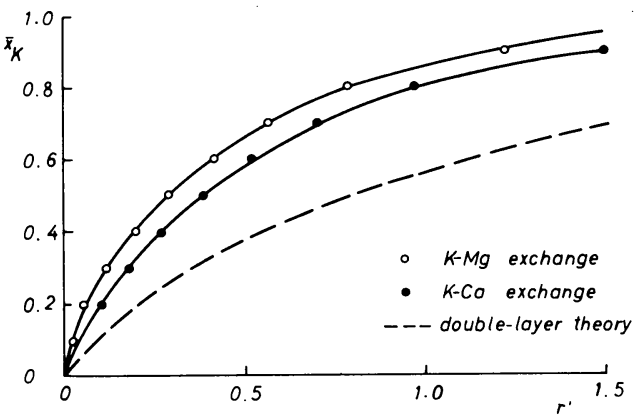

Fig. 4. Equivalent fraction of potassium in soil $\bar{x}_{K}$ in relation to the activity ratio $r^{\prime}$ calculated from double-layer theory in comparison to corresponding experimentally determined relations

tions have a similar form, the discrepancies are obvious. In some cases the double-layer theory is reported to describe adequately cation equilibriae.g., in systems of $\mathrm{Na}-\mathrm{Ca}$ illite (Bolt, 1955); K-Ca montmorillonite (Lagerwerff and Bolt, 1958); and Na-Ca soils (Pratt and Bair, 1962) - but in many cases-e.g., in other systems of $\mathrm{K}-\mathrm{Ca}$ illite (Lagerwerff and Bolt, 1958); K-Ca montmorillonite and kaolinite (Jensen, 1972c) ; and Na-Ca soils (Bower, 1959); Bower and Hatcher, 1962; Pratt et al., 1962, Pratt and Grower, 1964)-the double-layer theory has failed to describe the equilibria if not corrected with a factor for surface-charge density.

Table 6 lists experimental values of the thermodynamic equilibrium con-

Table 6

STANDARD FREE-ENERGY CHANGE AND THERMODYNAMIC EQUILIBRIUM CONSTANTS CALCULATED FROM DOUBLE-LAYER THEORY IN COMPARISON TO CORRESPONDING EXPERIMENTALLY DETERMINED VALUES

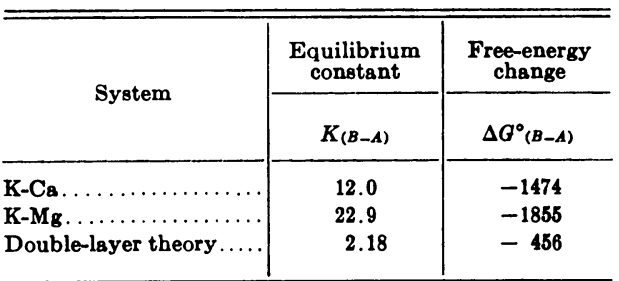


stant and the standard free-energy change for $\mathrm{K}-\mathrm{Mg}$ and $\mathrm{K}-\mathrm{Ca}$ systems together with corresponding values calculated from double-layer theory according to Jensen (1972c). According to these calculations the coulombic energy component of the standard free energy change is 25 and 30 per cent for $\mathrm{K}-\mathrm{Ca}$ and $\mathrm{K}-\mathrm{Mg}$ systems, respectively. The main part is therefore due to spe- cific interactions and is probably associated with specific adsorption of potassium ions. The adsorption may take place at the edges of clay minerals (Becket and Nafady, 1967) as well as at the planar surfaces as the potassium ion is of the right size to establish a favorable 12-coordination with opposite hexagonal oxygen rings of adjoining unit layers (Olphen, 1963).

\section{SUMMARY}

For several pairs of cation exchange, the properties of a Yolo loam soil were investigated. Cation-exchange isotherms at two ionic strengths for $\mathrm{K}-\mathrm{Na}, \mathrm{Mg}-\mathrm{Ca}$, $\mathrm{K}-\mathrm{Ca}$, and $\mathrm{K}-\mathrm{Mg}$ systems were obtained by using a leaching technique. For homovalent exchange systems, the isotherms were independent of ionic strength whereas in the case of heterovalent exchange systems the well-known valence or dilution effect appeared and greatly affected the course of the isotherms.

For each cation pair the values of the Vanselow selectivity coefficient were calculated at different exchanger compositions. For the systems involving $\mathrm{K}$ ions the Vanselow selectivity coefficient was dependent on ionic strength and indicated a selectivity for $\mathrm{K}$ over $\mathrm{Na}, \mathrm{Mg}$, and $\mathrm{Ca}$ which decreased with increasing $\mathrm{K}$-saturation. However, for the $\mathrm{Mg}$-Ca system the Vanselow selectivity coefficient was independent of ionic strength and exchanger composition, and indicated a constant selectivity for Ca over Mg. Thus soil may be considered as an ideal exchanger with regard to $\mathrm{Mg}-\mathrm{Ca}$ exchange, whereas for systems involving $\mathrm{K}$ the exchanger exhibits non-ideal exchanger behavior.

The respective values of the thermodynamic equilibrium constant, the standard free-energy change, and the individual activity coefficients of adsorbed cations were calculated by applying the Argersinger thermodynamic approach to the isotherms for the various exchange systems; all of these parameters were found to be independent of ionic strength. It is therefore concluded that the theory is valid for the cation-exchange systems considered. By means of the Vanselow selectivity coefficients, and the individual activity coefficients for adsorbed cations, the thermodynamic equilibrium constant could be recalculated for each data point.

The coulombic component of the standard free-energy change was calculated from double-layer theory. For K-Ca and $\mathrm{K}-\mathrm{Mg}$ systems the coulombic energy component was 25 and 30 per cent, respectively, of the total standard freeenergy change. Thus for these systems it is concluded that non-coulombic interactions between soil colloids and cations is predominant and is most likely to be specific adsorption of potassium ions.

For the heterovalent exchange systems studied, several exchange constants were compared to the Vanselow selectivity coefficient. It appeared that the Gapon exchange constant best fulfilled the condition of constancy and therefore may have practical application for this particular soil. However, the exchanger behavior may be better expressed by plotting the Vanselow selectivity coefficient and the individual activity coefficients for adsorbed cations against exchanger composition for the various ion pairs. 


\section{LITERATURE CITED}

Argersinger, W. J., A. W. Davidson, and O. D. Bonner

1950. Thermodynamics and ion exchange phenomena. Kansas Acad. Sci. Trans. 53:404-410.

BABCOCK, K. L.

1963. Theory of the chemical properties of soil colloidal systems at equilibrium. Hilgardia 34:417-542.

Babcock, K. L., R. M. Carlson, R. M. Schulz, and R. Overstreet

1959. A study of the effect of irrigation water composition on soil properties. Hilgardia 29: 155-70.

BoLT, G. H.

1955. Ion adsorption by clays. Soil Sci. 79:267-276.

1967. Cation exchange equations used in soil science-a review. Neth. J. Agric. Sci. 15:81-103.

Bower, C. A.

1959. Cation-exchange equilibria in soils affected by sodium salts. Soil Sci. 88:32-35.

Bower, C. A., and E. TRUoG

1940. Base exchange capacity determination as influenced by nature of the cation employed and formation of basic exchange salts. Soil Sci. Soc. Amer. Proc. 5:86-89.

Bower, C. A., and J. T. HATCheR

1962. Characterization of salt-affected soils with respect to sodium. Soil Sci. 93:275-80.

Davis, L. A.

1950. Ion exchange and statistical thermodynamics. J. Colloid Sci. 5:71-79.

DeIsT, J., and O. TALIBUDEEN

1967a. Ion exchange in soils from the ion pairs K-Ca, K-Rb and K-Na. J. Soil Sci. 18:125-37. $1967 b$. Thermodynamics of K-Ca ion exchange in soils. J. Soil Sci. 18:138-48.

EL-SAYEd, M. H., R. G. BuRAu, and K. L. BABCOCK

1970. Thermodynamics of Copper (II)-Calcium exchange on bentonite clay. Soil Sci. Soc. Amer. Proc. 34:397-400.

ERIKSSON, E.

1952. Cation exchange equilibria on clay minerals. Soil Sci. 74:103-13.

Gaines, G. L., and H. C. ThOMAs

1953. Adsorption studies on clay minerals. II. A formulation of the thermodynamics of exchange adsorption. J. Chem. Phys. 21:714-18.

1955. Adsorption studies on clay minerals. V. Montmorillonite-caesium-strontium at several temperatures. J. Chem. Phys. 23:2322-25.

GAPON, E. N.

1933. On the theory of exchange adsorption in soils. J. Gen. Chem. U.S.S.R. 3:144-63.

HARNED, H. S., and B. B. OwEN

1958. The physical chemistry of electrolytic solutions. Reinhold Pub. Corp. N.Y. Pp 645.

HuChEON, A. T.

1966. Thermodynamics of cation exchange on clay: Ca-K montmorillonite. J. Soil Sci. 17: 339-55.

JENSEN, H. E.

1972a. Cation adsorption isotherms derived from mass-action theory. Royal Vet. Agric. Univ. Copenhagen. Yearbook: 88-103.

1972b. Potassium-calcium exchange on a montmorillonite and a kaolinite clay. I. A test on the Argersinger thermodynamic approach. Agrochimica (in press).

1972c. Potassium-calcium exchange on a montmorillonite and a kaolinite clay. II. Application of double-layer theory. Agrochimica (in press).

JoHnson, C. M., and H. ULRICH

1959. Plant analysis and analytical methods. Calif. Agric. Sta. Bul. 766.

KERR, H. W.

1928. The nature of base exchange and soil acidity. J. Amer. Soc. Agron. 20:309-35.

KRISHNAMOORTHY, C., and R. Overstreet

1950. An experimental evaluation of ion exchange relationships. Soil Sci. 69:44-53.

LAGERWERFF, J. V., and G. H. BoLT

1959. Theoretical and experimental analysis of Gapon's equation for ion exchange. Soil Sci. 87:217-22.

Matson, S.

1929. The laws of colloidal behaviour. I. Soil Sci. 23:179-220. 
OLPHEN, H. VAN

1963. An introduction to colloid chemistry. Interscience Pub. N.Y. Pp 301.

Pratt, P. F., and F. L. BAIR

1962. Cation-exchange properties of some acid soils of California. Hilgardia 33:689-706.

Pratt, P. F., O. D. WhitTing, and B. L. Grover

1962. Effect of $\mathrm{pH}$ on sodium-calcium exchange equilibria in soils. Soil Sci. Soc. Amer. Proc. 26:227-30.

Pratt, P. F., and B. L. Grover

1964. Monovalent-divalent cation-exchange equilibria in soils in relation to organic matter and type of clay. Soil Sci. Soc. Amer. Proc. 28:32-35.

TABIKH, A. A., I. BARShad, and R. Overstreet

1960. Cation-exchange hysteresis in clay minerals. Soil Sci. 90:41-53.

VANSELOW, A. P.

1932. Equilibria of the base exchange reactions of bentonites, permutites, colloids and zeolites. Soil Sci. 33:95-113. 

The journal HILGARDIA is published at irregular intervals, in volumes of about 650 to 700 pages. The number of issues per volume varies.

Single copies of any issue may be obtained free, as long as the supply lasts; please request by volume and issue number from:

$$
\begin{aligned}
& \text { Agricultural Publications } \\
& \text { University of California } \\
& \text { Berkeley, California } \mathbf{9 4 7 2 0}
\end{aligned}
$$

The limit to nonresidents of California is 10 separate titles. The limit to California residents is 20 separate titles.

The journal will be sent regularly to libraries, schools, or institutions in one of the following ways:

1. In exchange for similar published material on research.

2. As a gift to qualified repository libraries only.

3. On a subscription basis- $\$ 7.50$ a year paid in advance. All subscriptions will be started with the first number issued during a calendar year. Subscribers starting during any given year will be sent back numbers to the first of that year and will be billed for the ensuing year the following January. Make checks or money orders payable to The Regents of The University of California; send payment with order to Agricultural Publications at above address. 